\title{
VEJEZ Y ENVEJECIMIENTO: \\ LA SOLIDARIDAD COMO PRINCIPIO BIOÉTICO
}

Fernando Lolas Stepke 


\section{FERNANDO LOLAS STEPKE}

Médico psiquiatra. Profesor titular de la Facultad de Medicina de la Universidad de Chile. Profesor asociado, Department of Psychiatry, University of Miami. Director del Centro Interdisciplinario de Estudios en Bioética de la Universidad de Chile. Académico de número de la Academia Chilena de la Lengua y académico correspondiente de la Real Academia Española. Doctor Honoris Causa por las universidades de San Marcos y Ricardo Palma (Perú), Córdoba y Cuyo (Argentina), además de profesor honorario de universidades en Europa, Estados Unidos y Latinoamérica. Director de Anales del Instituto de Chile y editor asociado de World Psychiatry. Ex Vicerrector de Asuntos Académicos y Estudiantiles de la Universidad de Chile y miembro del Comité Internacional de Bioética de UNESCO. 


\section{VEJEZ Y ENVEJECIMIENTO: \\ LA SOLIDARIDAD COMO PRINCIPIO BIOÉTICO ${ }^{1}$}

\section{RESUMEN}

Tras identificar como desafíos socialmente relevantes la vulnerabilidad y la discriminación que afectan a las personas que envejecen y la necesidad de proveer vida humana digna y plena a todos los miembros de la sociedad, se ofrece un examen preliminar del principio de solidaridad como complemento a los de autonomía, beneficencia, no maleficencia y justicia, más frecuentemente encontrados en la literatura bioética. Distinguiendo entre solidaridad mecánica y orgánica, con sus variantes y matices en el pensamiento cristiano y en las concepciones políticas, este artículo propone una consideración de este concepto en la formulación de políticas públicas y en el diseño de intervenciones. Se examina el Programa Interdisciplinario de la antigua Vicerrectoría Académica de la Universidad de Chile como ejercicio en solidaridad desde la academia. La valencia moral del concepto abre la pregunta por los modos en que debe ser entendida y puede ser fomentada.

\section{LOS DESAFÍOS: VULNERABILIDAD Y DISCRIMINACIÓN}

La vida humana es un continuo que se inicia con el nacimiento y termina con la muerte de los individuos. Suele describírsela mediante metáforas y dividirla con fines prácticos en etapas: niñez, adolescencia, madurez, vejez.

Como nunca antes en la historia humana, la contemporaneidad presenta el desafío de un crecimiento explosivo del número de personas con edades avanzadas. Por primera vez, personas muy jóvenes convivirán con personas muy añosas. Las poblaciones envejecidas demandarán distintos tipos de servicios, harán valer sus preferencias políticas y de consumo, precisarán distintas formas de apoyo social. El proceso de desvalimiento, que en las sociedades occidentales determina cambios en los papeles sociales y pérdida de poder y ascendiente, prescribe y proscribe comportamientos a sus miembros (Lolas, 2004).

Independientemente de sus causas (reducción de la mortalidad infantil, progresos de la medicina, mejores condiciones de salud pública), la transformación demográfica plantea desafíos inéditos. Aun con las esperanzas depositadas en la medicina genómica y en los avances de los sistemas sanitarios, el hecho ineludible y esencial es que la longevidad humana tiene límites y que el proceso de envejecer es universal. Todas las formas de negación, desde el "juvenilismo" hasta las sedicentes políticas públicas de "protección"

1. Durante la preparación de este artículo, el autor recibió apoyo del Grant NIH Fogarty R25 TW00605609 y de la Fundación Alexander von Humboldt (Alumni Preis). 
no consiguen eliminar la angustia de envejecer que se presenta, no en quienes ya son viejos sino en quienes anticipan la última etapa de la vida como plena de privaciones y decadencias. Los procesos sociales asociados a la pérdida de capacidades, a menoscabos, discapacidades y minusvalías que se asocian a la vejez, despiertan inquietud e incertidumbre, como lo demuestra el registro literario y la tradición común. Siempre se observa, no obstante, que "la senectud es ajena". Ni los mismos viejos se sienten viejos. El "yo interior" parece no envejecer nunca, aunque el "yo construido por los otros" (el self) sí lo hace, lo que provoca esas curiosas discrepancias entre lo sentido y lo imaginado, que constituyen una fuente de desazón para los senescentes (Lolas, 1996, 1997, 2001b).

Los desafíos consisten en proporcionar una vida de calidad a las personas que envejecen, sin merma de su dignidad y de su autonomía. En el plano individual, esto se traduce por aumentar las capacidades para "aprender a envejecer", proceso que puede llamarse gerogogía (Lolas, 1995, 2006). En el plano social, el desafío consiste en generar condiciones adecuadas para que las esperables diferencias individuales en los modos y estilos de envejecer sean respetadas. El miedo a la dependencia es mayor que el miedo a morir y no se aplaca con el paternalismo, que es la beneficencia sin autonomía. Como hemos señalado reiteradamente, la calidad de la vida es siempre subjetiva, tiene múltiples aspectos diversos y complementarios, no puede predicarse de manera uniforme en todos los ámbitos vitales y sus fundamentos cambian durante el ciclo vital. Esto significa que aquello que fundamentaba la autoestima en la juventud no cumple igual papel en la vejez y que los "satisfactores" y circunstancias generadoras de placer, aunque superficialmente sean semejantes, difieren en su valencia subjetiva y en su impacto real. Como señala Cicerón en De senectute, la Naturaleza, que es sabia, no solamente nos quita placeres; también nos priva del deseo de tenerlos. Esta afirmación, intuitivamente correcta, no puede universalizarse, especialmente porque el "efecto demostración" de una sociedad volcada a lo juvenil como factor de felicidad puede trastornar el fundamento del autoaprecio y obligar a comportamientos forzados e inauténticos en quienes envejecen (Lolas, 2006).

Considerar factores individuales y comunitarios supone examinar críticamente mitos como el de la familia extendida, que se supone caracteriza a algunas sociedades, o el de la reciprocidad generacional, que implicaría retribuir a los ancianos lo que han hecho por sus descendientes. La diferencia de género en las conductas altruistas lleva a esperar una "ética del cuidado" más acentuada en las mujeres, pero ello debe ser considerado también en el contexto de cambios esperables en los papeles sociales debidos a la clase social, grupos de pertenencia, universos creenciales y circunstancias individuales.

Los aspectos contextuales que han de tenerse en cuenta al reflexionar sobre los desafíos, aun cuando sean muy numerosos, pueden condensarse en dos: el grupo de las personas que envejecen experimenta una mayor vulnerabilidad y está sometido a diversas formas de discriminación. Independientemente de lo que se logre en el plano personal, estos factores de circunstancia social deben ser considerados al reflexionar sobre las metas de una política pública humana y digna.

Se trata, por tanto, de brindar a las personas la confianza en que serán atendidas sus necesidades de manera digna, que les serán brindados recursos que puedan administrar 
por sí mismas y que, con la incertidumbre que es propia de la vida, serán respetadas sus preferencias y diferencias.

\section{SOLIDARIDAD: UN CONCEPTO BIOÉTICO}

Más allá de la clásica enumeración de los principios de autonomía, beneficencia, no maleficencia y justicia, canónicos ya en la literatura bioética, explorar el concepto de solidaridad puede brindar una base más sustantiva a los desarrollos legislativos e institucionales requeridos para abordar los desafíos planteados (Lolas, 2008). El concepto tiene una larga utilización pero una breve historia de empleo consecuente, y precisamente en el ámbito de la salud pública ha llegado a adquirir prominencia. Nuestro objetivo es brindar sugerencias para su empleo en el diseño de políticas públicas relativas a la ancianidad (Lolas, 2001a).

Existen varias derivaciones posibles de la idea y de la palabra. Por de pronto, en el derecho romano el concepto de in solidum significaba una comunidad en la relación contractual, presuponiendo una sociedad en la cual los agentes individuales son autónomos para contraer obligaciones. Como concepto jurídico encontró lugar en el código napoleónico de 1804 y durante la Revolución francesa su significado se extendió al ámbito político, especialmente bajo la forma de fraternidad, destacando los lazos que unirían a los revolucionarios de corazón. Otros autores del siglo XIX destacaron las nociones de afinidad, semejanza o común destino como esenciales para afirmar el concepto (Prainsack y Buyx, 2011).

Debe distinguirse la solidaridad como hecho empírico comprobable de la solidaridad como prescripción de comportamiento. Cabe destacar la contribución de Émile Durkheim, quien distinguía entre solidaridad "mecánica", derivada de una similitud de orígenes, pertenencia a un grupo definido o familia o semejantes expectativas, y una solidaridad "orgánica", que nace con la división del trabajo y refleja la interdependencia en que se encuentran los individuos en sus afanes. Por ende, a la igualdad o similitud como fundamento, en el segundo sentido se agrega la complementariedad, que hace de lo solidario un basamento de la sociedad diferenciada en grupos por la división del trabajo. No están ajenos a esta distinción los clásicos conceptos de Gemeinschaft (la sociedad cara a cara, unida por lazos de afecto) y de Gesellschaft (la sociedad racionalmente constituida sobre el fundamento de la función social). En la tradición marxista-leninista, la conciencia de compartir un destino común, de clase, puede leerse como un fundamento del comportamiento solidario esperable de sus miembros (Prainsack y Buyx, 2011).

En la tradición cristiana, la noción de solidaridad encuentra sus orígenes en la fraternidad producida por la creencia común y por el hecho de que el Evangelio proclama el valor y la dignidad de todo ser humano y le hace por ende copartícipe del destino de toda la Humanidad. Es conveniente, a fin de despejar confusiones posibles, distinguir esta fraternidad-solidaridad del cristiano de la caridad frente al necesitado. Obsérvese que entre ambos conceptos la línea divisoria está trazada por la noción de igualdad. La caridad es concebible en una asimetría entre quien tiene y da y quien carece y recibe. De 
igual modo, a fin de depurar aun más el concepto y hacerlo útil para nuestra discusión, conviene reflexionar sobre sus vinculaciones con el altruismo. El comportamiento altruista tiene raigambre biológica y, en el fondo, se es buen egoísta cuando se es altruista si se considera que la supervivencia del individuo depende de la supervivencia del grupo. Al ser este la unidad actuante en el proceso evolutivo, tiene cierta coherencia ligar el beneficio propio al beneficio del conjunto. Lo cual no obsta para que, traspasada esta reflexión al plano humano, se observe que los más serios dilemas éticos suelen tener su origen en la preeminencia del individuo versus los intereses del conjunto. La salud pública y la economía internacional (poniendo a las naciones en el papel de individuos) son ejemplos que no precisan desarrollo.

Tomar las sociedades como puntos primarios de referencia suele asociarse con la idea del bien común, frecuentemente invocada en los discursos político y económico, con grados variables de consistencia. La mayor dificultad estriba en quien define qué es el bien común y qué valores o virtudes se necesitan para su consecución y perpetuación. Los universales de la práctica que llamamos virtudes, encarnando atributos de la acción que concebimos como valores, suelen no producir unanimidades y de hecho habitamos "comunidades de extraños morales" (y también de extraños "epistémicos", pues no sabemos todos lo mismo). En ellas, cada grupo definible posee sus propias definiciones del bien vivir y de lo que merece esfuerzo. La religión, relegada ya al plano de lo privado, no brinda las certidumbres necesarias para arribar a acuerdos. De allí pudiera distinguirse entre una solidaridad comunitaria, prácticas sociales existentes, y una solidaridad constituida por intereses aceptados en forma deliberada y consciente. Esta distinción es semejante a la ya mencionada entre solidaridad mecánica y orgánica.

La bioética es el uso del diálogo para arribar a certidumbres morales que permitan la convivencia en el seno de una cultura determinada. Enriquecer el diálogo con la noción de solidaridad puede ofrecer perspectivas razonables para fundamentar algunas soluciones a los desafíos que plantea el envejecimiento humano, como proceso biográfico y biológico, y la vejez, como etapa vital basada en atributos comunes a un grupo de individuos (Lolas y Drumond, 2007).

\section{SOLIDARIDAD, ENVEJECIMIENTO, VEJEZ}

En el año 1995 establecimos en la Vicerrectoría de Asuntos Académicos y Estudiantiles de la Universidad de Chile un Programa Interdisciplinario que tuvo a la vejez y el envejecimiento como sus núcleos de acción y reflexión. Participaron en él especialistas de diversas disciplinas y personas con distintas concepciones políticas y religiosas. De allí partió la contribución que se hizo a los estudios gubernamentales que luego constituirían una comisión presidencial para temas del adulto mayor y, finalmente, el Servicio Nacional del Adulto Mayor².

2. En las reuniones de aquella comisión presidencial participó, en nombre de la Universidad de Chile, la profesora Marta Glukman. 
Aparte la relevancia académica, que se concretó en aportaciones a los programas de especialización en geriatría y en reuniones que con apoyo de organismos internacionales examinaron dimensiones demográficas, sociales, éticas y biológicas del proceso de envejecer, el fundamento último puede ser releído hoy como un ejercicio en solidaridad. Un programa que ilustra bien esta orientación fue el de alfabetización de adultos mayores. Muchas personas nunca habían aprendido a leer y otras lo habían olvidado (Lolas, 1996). El programa, apoyado por el entonces Instituto Nacional de Previsión (INP), recuperó laboralmente a profesores jubilados, quienes entrenaron monitores, los cuales, a su vez, enseñaron a leer a ancianos y ancianas en todo el país. Se preparó un manual que condensa la orientación y las prácticas más efectivas para tal cometido. Mirado retrospectivamente, este fue un ejercicio en solidaridad desde la academia. Aquellas personas que se beneficiaron del programa habían perdido, o nunca tuvieron, posibilidad de actuar como ciudadanos y ciudadanas. Era una sumatoria de inequidades ser mujer, vivir en un medio rural y padecer de analfabetismo. Al remover una de las causas de inequidad y discriminación y -como dijo una participante- "hacer hablar a las letras", se les permitía acceder a un plano distinto de compartición de beneficios sociales. Empezando por saber cuáles podrían ser tales beneficios y demandarlos como derechos (Salas y Farías, 2000).

Es importante sugerir aquí las posibles aplicaciones del concepto de solidaridad, en sus diversas facetas, al problema planteado en nuestra sociedad por el envejecimiento y la vejez.

Por de pronto, podemos aceptar -al menos con un criterio estadístico- que los años cronológicos de una persona permiten segregar grupos: los mayores de sesenta, los mayores de setenta, etc. Bien sabemos que estas divisiones son artefactos y que los años cronológicos no necesariamente reflejan las realidades biográficas. Hay personas que ya son maduras y han hecho una vida creativa a los veinte y personas que a los ochenta nunca fueron miembros útiles para su comunidad. Sin dejarnos deslumbrar por la metáfora de las "etapas" o "edades" (a veces ampliada a las "tareas" y las "obligaciones" de cada una), algún factor diferenciador práctico introduce la edad. Este factor no es simple y debe tomarse solamente como orientación porque, como indicamos reiteradamente, no hay edad de la vida en que las diferencias entre las personas sean más marcadas e inutilicen tanto el criterio grupal como la vejez. Recuérdese lo que escribe Jonathan Swift sobre aquel país que visita Gulliver donde la gente no muere, solo envejece: los buenos se hacen mejores, los malos, peores. Tómese en consideración que incluso instrumentos psicométricos diseñados para medir rasgos estables de personalidad son sensibles al cambio etario.

Sin embargo, para los fines de formular políticas públicas, podemos aceptar la noción de que los ancianos y ancianas (mayores de cualquier edad que autorice a hablar de "tercera" o "cuarta" edad) son un grupo. Un grupo que, social y económicamente, aparece como vulnerable y discriminado. ¿Se aplicaría aquí la solidaridad mecánica o la solidaridad orgánica según Durkheim? La primera deriva de pertenecer "naturalmente" a familia, clase, oficio. La segunda, de la complementariedad del aporte de los grupos a los fines sociales. Confiamos que la familia, los compañeros de trabajo, los que profesan 
una misma fe, aplicarían una solidaridad mecánica y así subvendrían a las necesidades de apoyo y sostén de sus miembros. Pero la experiencia demuestra que, aun cuando eso ocurre en un porcentaje de casos, no es suficiente. Al hacer obligatoria la solidaridad mecánica mediante leyes se obtienen curiosos resultados y no siempre los más apropiados para el bienestar de los viejos. Esas leyes no pueden dictar la forma cómo debe ejercerse la solidaridad. Para algunos, puede bastar con dejar a los viejos de la familia bajo cuidados expertos, para otros pagar por su manutención u obligar a las mujeres solteronas a cuidarles.

La segunda aplicación del concepto, más general en sus alcances, es considerar que el grupo de los viejos y las viejas (fuera de todo eufemismo) puede entrar en relaciones de complementariedad (o, incluso, de reciprocidad) con otros grupos humanos. Esta solidaridad viene prescrita, como observábamos, por la división del trabajo pero podemos concebirla como la división de las aportaciones socialmente valiosas que hacen los distintos grupos y estamentos. Entendido así el asunto, la pregunta es: ¿en qué y cómo contribuyen los senescentes, en tanto grupo humano, al cuerpo social? La legislación podría recoger este matiz y hacerlo consciente para todos. Pero acontece que el aporte posible es justamente lo que está en entredicho. Hasta la forma de hablar lo anula: el "sector pasivo", se dice, no está en el proceso productivo directamente. La seguridad social debe hacerse cargo de él, recurriendo al Estado o al mercado. El cambio histórico operado en las concepciones sobre el bienestar social es lo que hace difícil prescribir una solidaridad orgánica. Antes, los viejos eran los depositarios de los valiosos bienes de la memoria colectiva; reemplazaban a los libros y evitaban experimentaciones inútiles a los jóvenes. El ciudadano corriente de hoy no recurriría a los viejos de su entorno para saber algo (para eso tiene Google), solamente para extrañarse de cómo vivía esa pobre gente antes de que existieran los teléfonos celulares o los computadores y todavía se usaban los sellos postales para transmitir mensajes.

Pareciera que ambos aspectos de la solidaridad, aplicados al grupo etario "tercera edad", encuentran dificultades para su aplicación general. Pareciera que distinguir como grupo a los viejos y viejas (de nuevo, eufemismos aparte) no sería buena estrategia, pues en todo caso se llega a imponer la solidaridad. Y las virtudes, como los principios morales "de máximos", no se pueden forzar. Nadie puede ser forzado a ser bueno o a hacer el bien. Pero sí puede ser obligado a respetar a los demás y a no dañarlos. Esta ética de mínimos puede también refrasearse en relación con la solidaridad.

Así como todo buen egoísta es altruista y se preocupa del grupo cuando descubre que no hay un "yo" viable sin un "nosotros" sólido, la solidaridad para los que envejecen podría basarse en que al fin de cuentas comparten nuestro común destino. Esta forma de concebir el asunto podría llevarnos a la noción de reciprocidad ("do ut des"), que hemos explorado también en relación con el tema del envejecimiento. Si no salvo mi "circunstancia vital" (en la que incluyo a los ancianos) no podré salvarme yo. Esta perspectiva es abstracta y difícilmente podría convencerse a la gente de trabajar por ancianos y ancianas que no conoce, por más parte de su ecosistema que se le diga que son.

Una vertiente digna de exploración es la solidaridad en su raigambre cristiana. No se trata, decimos, de ejercer la caridad, que siempre implica una relación asimétrica (doy 
yo porque tengo, recibes tú porque necesitas). Una solidaridad en la dignidad de ser humano es lo que procede. Compartimos un común destino, compartimos una vocación salvífica que nos abarca como personas y creaturas de Dios. La debilidad del argumento reside en que no todos los miembros de una sociedad son cristianos o tienen por buena la Palabra de Dios. Incluso, los que creen en ella, descreen que les obligue a amar al prójimo, más si este prójimo es viejo, pobre, necesitado y demandante.

\section{ALGUNOS COROLARIOS}

Al realizar el ejercicio preliminar, de reflexionar sobre la solidaridad como fundamento de soluciones a los desafíos que plantean el envejecimiento y la vejez, aparece una dimensión que amplía el tradicional discurso bioético principialista basado en el "mantra de Georgetown" de autonomía, beneficencia, no maleficencia y justicia. Es posible argumentar que la solidaridad ofrece matices y perspectivas más profundas, o al menos diferentes, que el concepto de justicia distributiva, o equidad, usualmente empleado en discusiones de salud pública (Lolas, 2008). Hemos limitado este análisis preliminar a los senescentes como receptores de solidaridad, pero obviamente existe para ellos, como grupo, también la opción de ejercerla. Una acción moralmente apropiada puede, por ejemplo, consistir en la renunciación a beneficios o favores en pro de la salud del conjunto. Se trata ciertamente de una posibilidad teórica compleja, que más de algún autor ha elaborado a riesgo de ser tildado de totalitario. Exigir renunciación y sacrificio a los viejos, como parece indicarlo alguna tradición recogida por la etnografía de pueblos que valoran menos la individualidad, no puede imponerse, como no puede imponerse la solidaridad de los jóvenes hacia los viejos. Al examinar distintos conceptos relevantes para promover buena vida en la vejez, hemos observado que ni el concepto de necesidad ni el de reciprocidad contractual son satisfactorios y puede anticiparse que no movilizarán las conciencias ni la imaginación moral.

Sin perder de vista los fines -esto es, responder a los desafíos de la vulnerabilidad y la discriminación- parece relevante continuar profundizando sobre la noción de solidaridad como un principio de vieja raigambre que podría complementar el tratamiento habitual de los derechos de las personas, la dignidad de la vida y el carácter inalienablemente humano de ser persona en una sociedad.

\section{REFERENCIAS BIBLIOGRÁFICAS}

Lolas, F, "Gerogogía: enseñar a envejecer como tarea social", en su Ensayos sobre ciencia y sociedad, Buenos Aires: Estudio Sigma, 1995, págs. 71-74.

- (ed.), "Vejez y envejecimiento en América Latina y el Caribe. Aspectos demográficos y bioéticos", en Cuadernos de Extensión de la Vicerrectoría Académica, Santiago de Chile, Universidad de Chile, Vicerrectoría de Asuntos Académicos y Estudiantiles, 1996. 
- Estudio cualitativo de la calidad de vida en el senescente. Una propuesta metodológica, Buenos Aires: Vertex, 8, 1997, págs. 193-195.

— "Dimensiones bioéticas del cuidado médico en el anciano", en Revista Médica de Chile, Santiago, 125, 1997, págs. 1024-1026.

—— "Las dimensiones bioéticas de la vejez", en Acta Bioethica, 7(1), 2001ª págs. 57-70.

"Ethics and Quality of Life in the Elderly", en Weisstub, D.N., Thomasma, D.C., Gauthier, S., Tomossy, G.F. (eds.), Aging: Decisions at the end of life, Dordrecht: Kluwer, 2001b, págs. 21-30.

— "Envejecimiento y vejez. Desafíos bioéticos y calidad de vida", en Acosta Sariego, J. (ed.), Bioética para la sustentabilidad, La Habana: Centro Félix Varela y Publicaciones Acuario, 2002a, págs. 373-394.

- Bioética y Medicina, Santiago: Editorial Biblioteca Americana, 2002b.

— Consideraciones sobre vulnerabilidad social, La Plata: Quirón, 35, 2004, págs. 45-51.

— "Evitar la distanasia tecnocrática: objetivo de los cuidados paliativos", en Ars Medica, Pontificia Universidad Católica de Chile, № 11, 2005, págs. 17-22.

- Escritos sobre vejez, envejecimiento y muerte, $2^{\mathrm{a}}$ edición, Iquique: Campus, 2002.

— Drumond, J.G. de Freitas, Fundamentos de uma antropología bioética. O apropiado, o bom e o justo, Sao Paulo: Edicoes Loyola y Centro Universitario Sao Camilo, 2007.

— "La bioética como filosofía social en la formulación de políticas públicas. Consideraciones sobre epistemología, sustentabilidad y sostenibilidad", en Cuneo, A., Mena, C. y Pizarro, C. (eds.), Estudios de Derecho Privado, Santiago: Editorial Jurídica de Chile y Fundación Fernando Fueyo Laneri, 2008, págs. 607-615, (Libro Homenaje al profesor Gonzalo Figueroa Yáñez).

— "El desafío de la vejez hacia el futuro", en Revista de Derecho de la Universidad Finis Terrae, XIII (13), Santiago de Chile, 2009, págs. 137-146.

Prainsack, B., Buyx, A., Solidarity. Reflections on an Emerging Concept in Bioethics, Londres: Nuffield Council on Bioethics and Arts and Humanities Research Council, 2011.

Salas, G., Farías, A., Palabra en Blanco, Santiago, Universidad de Chile, Vicerrectoría de Asuntos Académicos y Estudiantiles, 2000. 